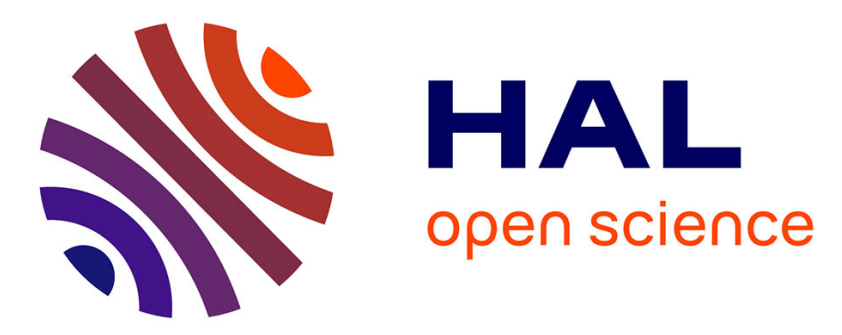

\title{
An Optimal Integrated Maintenance for Multi Parallel Workstations Under Returned Products
}

Tarek Askri, Zied Hajej, Nidhal Rezg

\section{To cite this version:}

Tarek Askri, Zied Hajej, Nidhal Rezg. An Optimal Integrated Maintenance for Multi Parallel Workstations Under Returned Products. IEEE International Conference on Industrial Engineering and Engineering Management (IEEM 2015), Dec 2015, Singapour, Singapore. pp.747-751, 10.1109/IEEM.2015.7385747 . hal-01338334

\section{HAL Id: hal-01338334 \\ https://hal.science/hal-01338334}

Submitted on 28 Jun 2016

HAL is a multi-disciplinary open access archive for the deposit and dissemination of scientific research documents, whether they are published or not. The documents may come from teaching and research institutions in France or abroad, or from public or private research centers.
L'archive ouverte pluridisciplinaire HAL, est destinée au dépôt et à la diffusion de documents scientifiques de niveau recherche, publiés ou non, émanant des établissements d'enseignement et de recherche français ou étrangers, des laboratoires publics ou privés. 


\title{
An Optimal Integrated Maintenance for Multi Parallel Workstations Under Returned Products
}

\author{
T. Askri, Z. Hajej, N. Rezg \\ Université de Lorraine, Metz, France \\ tarek.askri@univ-looraine.fr, zied.hajej@univ-lorraine.fr, nidhal.rezg@univ-lorraine.fr
}

\begin{abstract}
This paper treaties an integrated maintenance problem of manufacturing system with considering a returned products and leasing constraints. We have established an economical production policy and an optimal maintenance strategy for a production system composed by numerous parallels workstations. The system contains a numerous machines to meet a random demands, respecting a certain service level and with considering the returned product (withdrawal right). Firstly, to obtain an economical production planning, we minimize the total production cost. Secondly, according to obtained production plan, we determine the optimal maintenance strategy for different leased machines. The main is to show the impact of the returned products on the production plan and the production rates on the degradation degree of machines.
\end{abstract}

Keywords-Production and maintenance planning, preventive maintenance, minimal repair, Service level, Multi parallel leased machines, returned products.

\section{INTRODUCTION}

Random Failure, random demand, availability and reliability of equipment's are considered among the uncertainties that influenced on the production and maintenance policies of manufacturing systems. Facing these uncertainties, the companies choose a policy of collaboration and cooperation with other enterprises. In this context, the leasing is considered as a best solution in term of cost since more industries have preferred leasing rather than owning it. [3] shows the importance of the leasing and presented the causes of equipment leasing that the cost of purchase of new equipment is increasing.

Concerning maintenance while leasing equipment, [7] considered a mathematical formulation for a maintenance policy characterized by a minimal repair in the case fails of equipment. When the equipment age spreads a certain threshold value, an imperfect preventive maintenance is approved. Finally, they illustrated the effects of the number of lease periods and the maintenance strategy on the total cost by a numerical example. Recently, [8] proposed an analytical study and a numerical example in order to obtain the optimal maintenance policy and the length of the lease period by showing the impact of the optimal lease period and the maintenance strategy for profit model.

Concerning production and maintenance optimization of single or multiple manufacturing machines, [5] proposed and minimized a mathematical model of manufacturing system of numerous identical workstations and subjected to reparation periods, in order to control the production level and the reparation date. [4] minimized a total production and maintenance cost for production system of various workstations considering the failure prone manufacturing system. [2] treated the optimality of a production system using the hedging point policy which the machine failure rate be determined by the production level. [6] proposed a jointly stock and maintenance optimization in a production system of numerous machines.

This work is the continuation of [1] and [9] works. [1] dealt with a production scheme contains numerous similar workstations which has to meet a random demand respecting a certain service level. The objective is to determine the optimal production plan characterized by the optimal number of machine, facility time and inventory levels. [9] deals the same problem of [1] considering the influence of the returned product by the market on the optimization problem. In our work, we propose a production and maintenance strategies where the production rate depend to the returned products and the maintenance strategy be determined according to the economical production plan where the degradation of equipment is influenced by the variation of production rates. Consequently, an optimal combination of workstations amount, manufacture level, and inventory levels is proposed to meet the random demand under facility level. A maintenance strategy is developed to establish the optimum number of preventive maintenance actions for all leased machines by minimizing the total maintenance cost.

This paper is planned as follow: Section II proposes the methodology followed and discusses the mathematical model of production system by presenting the different costs. Section III presents a simple numerical example and gives the results. Discussions are proposed in section IV.

\section{PRODUCTION AND MAINTENANCE FORMULATION}

\section{A. Production Planning \\ 1) Notations}

$H . \Delta t$ : finite production time horizon.

$\Delta t$ : production period

$\delta$ : rate of returned product . 
$M_{k}$ : workstation number at each period $k$.

$U_{k}$ : production rate at each period $k$.

$u_{i k}$ : amount of products of machine $i$ at period $k$.

$\mathrm{S}$ : level of inventory at each period $k$.

$M$ : upper bounds of leasing machines number at period $k$. $m$ : lower bounds of leasing machines number at period $k$. $\mathrm{u}$ : amount of production for each machine per time unit (hour); (the same for all machines).

$X_{i k}^{N}$ : Normal time units (hours) of machine $i$ at period $k$.

$X_{i k}^{S}$ : Over time (hours) of machine $i$ at period $k$.

$X_{\max }^{N}$ : upper bounds of normal time at period $k$.

$X_{\max }^{S}$ : upper bound of overtime at period $k$.

$\mathrm{c}_{1}$ : machine leasing cost.

$\mathrm{c}_{2}$ : constant leasing cost.

$c_{3}$ : Cost of machine number variation

$\mathrm{c}_{4}$ : Asymmetry Coefficient.

$c_{0}:$ Overtime cost

$\mathrm{c}_{\mathrm{n}}$ : Cost of unused normal time

$\mathrm{c}_{\mathrm{h}}$ : Inventory cost.

$M_{p}$ : unit preventive maintenance cost

$M_{c}$ : unit corrective maintenance cost

\section{2) Problem description}

This study consists with production system a several parallel leased machines that produces periodically one type of product. The random demands are satisfied from the store $\mathrm{S}$ during a finite production horizon. The customer demands are random and characterized by a Gaussian distribution with first and second statistical moments given respectively, by $\hat{d}$ and $\sigma_{d}^{2}$. The satisfaction of the request is made at the end of each period under a given service level $\theta$. The production system takes into account the withdrawal right where the customers have the right to return a quantity of products to stock $\mathrm{S}$ provided that it still in new and saleable conditions, before a fixed deadline $\tau_{r}$. The normal work hours of each machine is characterize by a upper bound time units $X_{\max }^{N}$ for each production period and the overtime of each machine, when the amount of demand is greater to production quantity, not exceeds the upper bound of time units $X_{m a x}^{S}$. The production system is characterize by the variation of leasing workstations number between the different productions periods according to the amount of returned product from market and production rates.

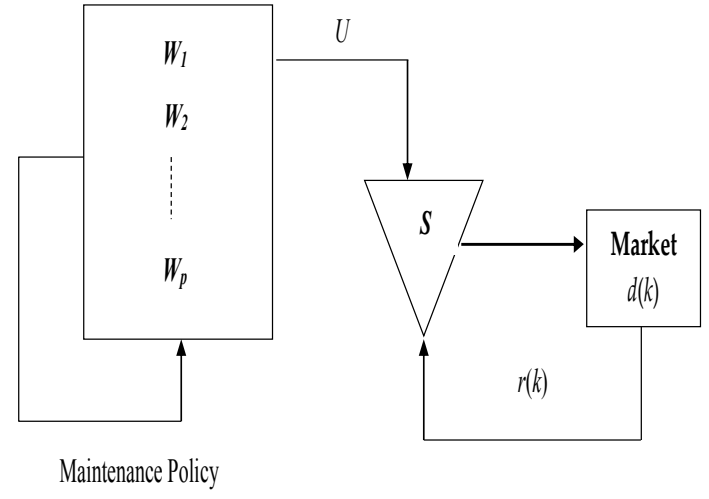

Fig. 1. Problem Description

The goal is to determine an optimal production plan and an optimal maintenance strategy. The production policy characterized by the variation of leased machines number and the returned products constraint. The impact of withdrawal right is justified by the impact returned production on the production system and consequently on the maintenance plan whose the degradation degree of machines influenced by the production rates.

\section{3) Problem formulation}

The decision variables of the stochastic model are the number of leased machines and the production rate $\left(W_{k}^{*}, U_{k}^{*}\right)$ according to normal and overtime times of machine work $\left(X_{i k}^{N}, X_{i k}^{S}\right)$.

The total production cost considering: the leasing cost; the installation and removal cost where the number of the machines varied from period to another; the cost of overtime work based on a binary variable $\theta_{k}$ that equal to 1 when the quantity of demand at production period $k$ surpasses the production quantity and all used machines $M_{k}$ work with upper bound normal time and equal to 0 ; the cost of inventory and unexploited capacities cost, is defined as follows: 


$$
\begin{aligned}
& \min _{\left(M_{k}, X_{i k}^{N}, X_{i k}^{S}\right)} C T
\end{aligned}
$$

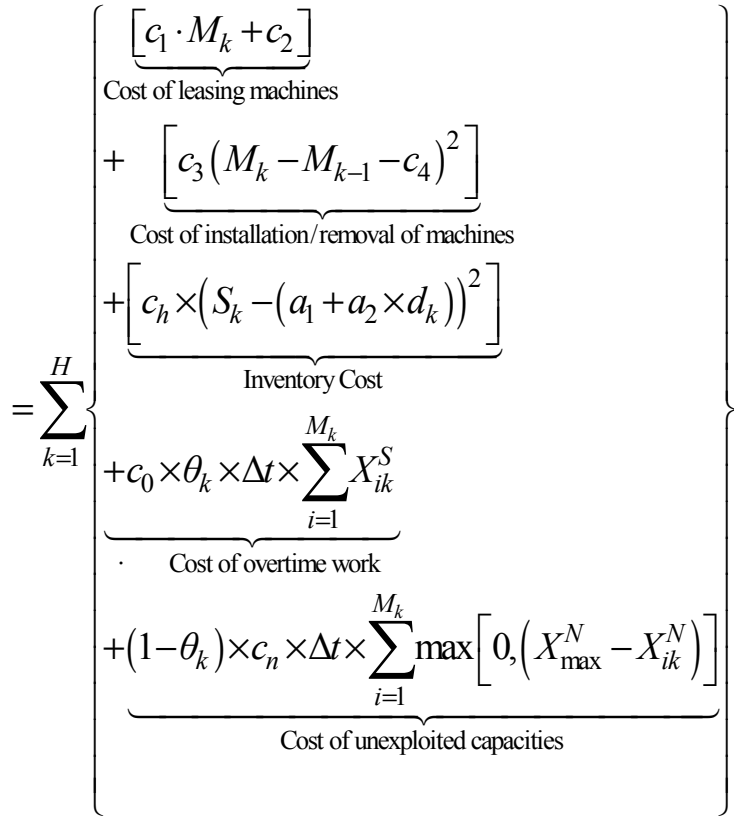

Subject to

$$
\begin{aligned}
& S_{k}=S_{k-1}+U_{k}-d_{k}+r_{k} \\
& \text { with } k=1, \ldots . ., H-1 \\
& r(k)=\left\{\begin{array}{cl}
\delta \cdot d\left(k-\frac{\tau_{r}}{\Delta t}\right) & \text { if } k \geq \tau_{r} \\
0 & \text { otherwise }
\end{array}\right. \\
& k=1, \ldots . ., H-1, \tau_{r}=h \cdot \Delta t \text { and } h \geq 1 \\
& U_{k}=u \times \Delta t \times \sum_{i=1}^{W_{K}}\left(X_{i k}^{N}+X_{i k}^{S}\right) \\
& \operatorname{Prob}\left(S_{k} \geq 0\right) \geq \boldsymbol{\alpha} \\
& m \leq M_{k} \leq M \\
& 0 \leq X \underset{i k}{N} \leq X \underset{\mathrm{max}}{N} \\
& 0 \leq X \underset{i k}{S} \leq X \underset{\mathrm{m} \mathrm{ax}}{S}
\end{aligned}
$$

Where the relation (1) describes the cumulative equation of inventory for each period $k$ take into account the quantity of returned product. The constraint (2) represents the product amount returned from the market after a specific deadline. The equation (3) computes the production rate at each production period depending to the work times of each workstations and the production quantity of each machine. The service level for each period is given by the constraint (4). The constraint (5) defines the upper and lower number of leased machines at each production period. Finally, the last constraints (6) and (7) define the upper and lower bound of normal and over time work variables.

\section{B. Analytical Study}

In this section, we proposed an analytical study in order to simplify the expected total cost by transforming our stochastic problem to a deterministic corresponding problem.

The mean variables are following:

$$
E\left\{S_{i, k}\right\}=\hat{S}_{i, k} ; E\left\{U_{k}\right\}=U_{k} ; E\left\{M_{k}\right\}=M_{k} ; E\left\{X_{i k}^{N}\right\}=X_{i k}^{N}
$$

;E $\left\{X_{i k}^{S}\right\}=X_{i k}^{S}$

And the variances: $V_{U_{k}}=0, V_{W_{k}}=0, V_{X_{i k}^{N}}=0, V_{X_{i k}^{S}}=0$.

We can obtain the simplified cost:

$$
\operatorname{Min}_{\left(M_{k}, U\right)}\left\{\sum_{k=1}^{H}\left\{\begin{array}{l}
\left(c_{1} \cdot M_{k}+c_{2}\right)+\left(c_{3} \cdot\left(M_{k}-M_{k-1}-c_{4}\right)^{2}\right) \\
+c_{o} \cdot \theta_{k} \cdot \Delta t \cdot \sum_{i=1}^{M_{k}} X_{i k}^{S} \\
+\left(1-\theta_{k}\right) \cdot c_{n} \cdot \Delta t \cdot \sum_{i=1}^{M_{k}} \max \left[0,\left(X_{\max }^{N}-X_{i k}^{N}\right)\right] \\
+c_{h} \cdot\left(\hat{S}_{k}-\left(a_{1}+a_{2} \cdot \hat{d}_{k}\right)\right)^{2} \\
+\left(1+a_{2}\right)^{2} \cdot V_{d} \cdot \frac{H}{2} \cdot(H+1)+a_{2}^{2} \cdot V_{d} \cdot \frac{H}{2} \cdot(H-1)
\end{array}\right\}\right.
$$

With

$$
\text { as: } \hat{S}_{k}=\left\{\begin{array}{l}
\hat{S}_{k-1}+U_{k}+\boldsymbol{\delta} \cdot \hat{d}_{\left(k-\frac{\boldsymbol{\tau}_{r}}{\Delta t}\right)}-\hat{d}_{k} \quad \text { If } k \geq \boldsymbol{\tau}_{r} \\
\hat{S}_{k-1}+U_{k}-\hat{d}_{k} \quad \text { If } k<\boldsymbol{\tau}_{r}
\end{array}\right.
$$

\section{- Chance-constraint}

The difficulty of solving this stochastic problem optimization requires us to converted the chanceconstraint characterized the service level to equivalent deterministic problem that preservers original properties.

$\operatorname{Prob}\left(S_{k} \geq 0\right) \geq \alpha \Rightarrow\left(\begin{array}{l}U_{k} \geq\left(\begin{array}{l}V_{d_{k}} \times V_{d_{k-\tau_{r}}} \\ -S_{k-1}+\hat{d}_{k}-\delta \cdot \hat{d}_{k-\tau_{r}}\end{array}\right) \times \varphi^{-1}(\alpha)\end{array}\right) \quad k=0,1, \ldots, H-1$

$\varphi$ is a Gaussian cumulative distribution function with mean $\quad \frac{1}{V_{d, k-\tau_{r}}} \cdot \hat{d}_{k}-\frac{\delta}{V_{d}} \cdot \hat{d}_{k-\tau_{r}} \quad$ and $\quad$ finite variance $\left(\left(\frac{1}{V_{d, k-\tau_{r}}}\right)^{2} \cdot V_{d, k}+\left(-\frac{\delta}{V_{d}}\right)^{2} \cdot V_{d, k-\tau_{r}} \geq 0\right)$. 


\section{Maintenance Planning Problem}

Considering the developed production planning, we are able to determine the maintenance strategy which allows minimizing its total cost. We assumed in the maintenance strategy a preventive maintenance action with minimal overhaul practiced in periods $(h \times T)(h=1,2 \ldots)$.

Assuming that the times of repair and replacements are negligible, the aim of the maintenance strategy is to determine the optimal number of preventive maintenances $N^{*}$ that minimize the total cost as well as the minimal preventive maintenance interval. The relationship between $N^{*}$ and $T^{*}$ is given by:

$$
N^{*}=\left\lfloor\frac{(H-1)}{T^{*}}\right\rfloor
$$

Assuming that the machines degradation is linear and the failure rate is increased according to time and production level.

Dealing with multiple leased machines, the evolution of the equipment failure rate is presented as follows:

$$
\lambda_{i k}(t)=C_{i k} \cdot \lambda_{i(k-1)}(\Delta k)+\frac{p_{i k} / \Delta k}{u_{\max }} \cdot \lambda_{n}(t) \forall t \in[0, \Delta t]
$$

Where:

$\lambda_{n}(t)$ represents the nominal workstation failure rate

$p_{i k}$ represents the quantity of product for workstation $i$ at period $k$

$$
p_{i k}=\Delta k \times u \times\left(X_{i k}^{N}+X_{i k}^{S}\right)
$$

$u_{\max }$ is the maximum production rate of a workstation

$$
u_{\text {max }}=u \times\left(X_{\text {max }}^{N}+X \underset{\text { max }}{S}\right) / \Delta t
$$

$C_{i k}$ is a binary variable presented as follows:

$C_{i k}=\left\{\begin{array}{l}1 \text { if workstation } \mathrm{i} \text { has been used during period k-1 } \\ 0 \text { if no }\end{array}\right.$

The total maintenance cost is formed by two cost functions related to preventive and corrective maintenance actions and is expressed as follows:

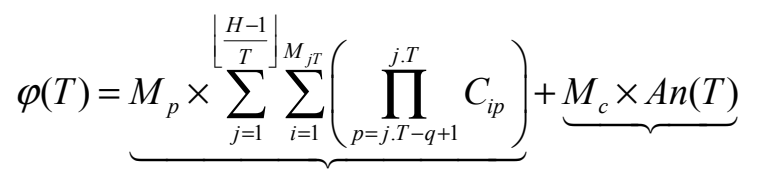

For the preventive maintenance cost is given by the unit maintenance cost multiply by the number of machine on which the maintenance will be applied.
We assume that preventive actions should not be performed on all machines used in period $j . T^{*}$ but only in machines used at last in $q$ periods with

$$
q= \begin{cases}1 & \text { if } T \leq 2 \\ 2 & \text { if } n o\end{cases}
$$

The second part of total maintenance cost is the corrective maintenance cost where $A n(T)$ represents the average number of failures until the last preventive action and considering the periods $j \in\left\{1,2, . ., N_{T}\right\}$ and during the last periods $\in\left\{N_{T+1}, N_{T+2}, . ., H\right\}$.

$A n(T)$ is formulated as follows:

$$
A n(T)=\sum_{j=0}^{\left\lfloor\frac{(H-1)}{T}\right\rfloor_{k=j . T+1}^{-1}} \sum_{i=1}^{(j+1) \cdot T} \int_{0}^{M_{k}} \lambda_{i k}^{\Delta t}(t) d t+\sum_{k=\left[\frac{(H-1)}{T}\right]}^{H} \sum_{T+1}^{M_{k}} \int_{0}^{\Delta t} \lambda_{2 i k}(t) d t
$$

Where:

$$
\lambda_{1 i k}(t)=\left[\sum_{p=j \cdot T+1}^{k-1}\left(\prod_{p^{\prime}=p}^{k-1} C_{i \cdot\left(p^{\prime}+1\right)}\right) \times \frac{P_{i p} / \Delta k}{u_{\max }}\right] \lambda_{n}(\Delta t)+\frac{P_{i k} / \Delta k}{u_{\max }} \times \lambda_{n}(t) ; t \in[0, \Delta t]
$$

And

$\lambda_{2 i k}(t)=\left[\sum_{p=\left[\frac{(H-1)}{\alpha} \mid{ }^{\prime} \alpha+1\right.}^{k=1}\left(\prod_{p^{\prime}=p}^{k=1} C_{1\left(p^{\prime}+1\right)}\right) \times \frac{p_{i p} / \Delta k}{u_{\max }}\right] \times \lambda_{n}(\Delta t)+\frac{p_{i k} / \Delta k}{u_{\max }} \times \lambda_{n}(t)$

\section{RESULTS}

Using the models described in previous section, a numerical example is presented to determine the economical production plan and the optimal maintenance strategy. The production horizon $\mathrm{H}$ is equal to 5 periods and the length of each period $\Delta t$ is equal to 25 days duration.

with $\sigma_{d}=1.1$, is constant for all periods and the initial inventory level $S_{0}=0$.

The other data are given in sequence.

$c_{1}=500 ; c_{2}=0 ; c_{3}=3.88 ; c_{4}=2.42 ; c_{o}=7 ; c_{n}=5 ; c_{h}=10 ;$ $a_{1}=250 ; a_{2}=0$;

- $\tau_{r}=1 ; \delta=0.1 ; u=15$

- : lower bounds $m=6$ machines; upper bounds $M=9$ workstations; upper bound of normal time work $X_{\max }^{N}=6$; and over time $X_{\max }^{S}=2$;

- Probabilistic index $(\alpha=0.9)$.

The input data concerning the average demand is listed in tables I

Table I: Average of stationary demand

\begin{tabular}{|l|l|l|l|l|}
\hline$\hat{d}_{1}$ & $\hat{d}_{2}$ & $\hat{d}_{3}$ & $\hat{d}_{4}$ & $\hat{d}_{5}$ \\
\hline 2286 & 22853 & 11880 & 15123 & 20653 \\
\hline
\end{tabular}


Using a numerical procedure method, an economically production plan and an optimal number of workstations are obtained and consequently the planning of normal time of production. The results are exhibited respectively in table II, III.

Table II: Economical leasing machines and production plans

\begin{tabular}{|l|l|l|l|l|l|}
\hline $\boldsymbol{k}$ & $\boldsymbol{k}=\mathbf{1}$ & $\boldsymbol{k}=\mathbf{2}$ & $\boldsymbol{k}=\mathbf{3}$ & $\boldsymbol{k}=\mathbf{4}$ & $\boldsymbol{k}=\mathbf{5}$ \\
\hline $\boldsymbol{M}_{\boldsymbol{k}}$ & 7 & 8 & 7 & 7 & 8 \\
\hline $\boldsymbol{U}_{\boldsymbol{k}}$ & 11250 & 18250 & 12750 & 12750 & 19500 \\
\hline
\end{tabular}

Table III: Normal work time planning of each workstation

\begin{tabular}{|l|l|l|l|l|l|}
\hline Periods $\boldsymbol{k}$ & $\boldsymbol{k}=\mathbf{1}$ & $\boldsymbol{k}=\mathbf{2}$ & $\boldsymbol{k}=\mathbf{3}$ & $\boldsymbol{k}=\mathbf{4}$ & $\boldsymbol{k}=\mathbf{5}$ \\
\hline W1 & 4 & 6 & 4 & 4 & 6 \\
\hline W2 & 4 & 4 & 5 & 4 & 5 \\
\hline W3 & 4 & 6 & 4 & 6 & 6 \\
\hline W4 & 4 & 4 & 5 & 5 & 4 \\
\hline W5 & 4 & 4 & 4 & 4 & 6 \\
\hline W6 & 5 & 5 & 4 & 6 & 5 \\
\hline W7 & 5 & 6 & 4 & 6 & 5 \\
\hline W8 & 0 & 6 & 0 & 0 & 6 \\
\hline W9 & 0 & 0 & 0 & 0 & 0 \\
\hline
\end{tabular}

For the maintenance strategy, using the results of the production planning, the maintenance scheduling can now be improved with $M_{p}=500 \mathrm{mu}$ and $M_{c}=2000 \mathrm{mu}$

The machine number vector with these production inputs and considering $\delta=0.1$ (optimal value of returned products) is illustrated as follows: $\boldsymbol{M}_{\boldsymbol{k}}=\mathbf{( 7 , 8 , 7 , 7 , 8 )}$

We assume that the nominal failure rate function follows

a Weibull distribution given by: $\lambda_{n}(t)=\frac{\gamma}{\beta} \cdot\left(\frac{t}{\beta}\right)^{\gamma-1}$

With these parameters $\alpha=2$ and $\beta=100$.

According to the units costs of preventive and maintenance actions, we obtained the optimal preventive maintenance interval $T^{*}$ as well as the optimal number of preventive maintenance actions $N^{*}$.

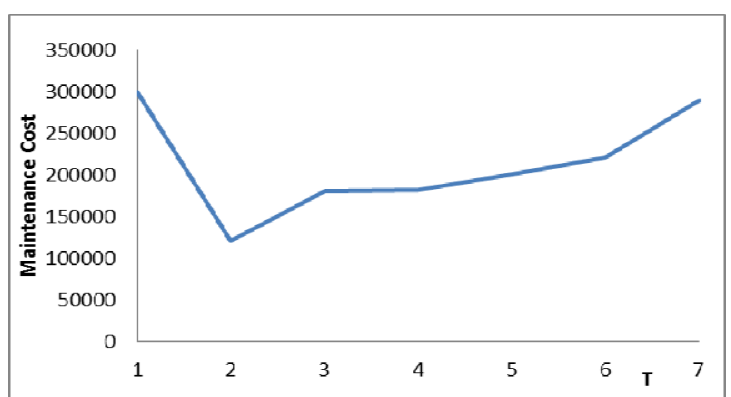

Fig. 2. Total Maintenance cost according to $\mathrm{T}$

From figure 2, we can conclude that the optimal preventive maintenance interval is equal to $T^{*}=2$ where we obtain the lowest maintenance cost that equal to $\varphi\left(T^{*}\right)=28000 \mathrm{um}$. And in this case, we can apply two preventive maintenance actions $\left(N^{*}=2\right)$;

\section{DISCUSSION}

According to the results given in the previous section, we can note that more the interval between preventive maintenance actions is high more the maintenance total cost is increasing. In fact, the machines to which preventive actions are not applied are more subjects to breakdowns. Then, expensive corrective actions are applied. Otherwise, in the case of applying preventive actions more frequently, it also leads to increase the total maintenance cost.

\section{CONCLUSION}

This study presented a stochastic production and maintenance planning problem for a numerous leased workstations. To satisfy the random demand and minimize the costs of production and maintenance, we establish a best combination between the variation of machines number, the production rates (as well as normal and over time planning of work) for each leased workstation, the inventory level and the returned products and we determine the optimal strategy maintenance characterising by the optimum number of preventive maintenance actions for all leased machines by showing the impact of production rates on the degradation degree of equipment's and consequently on the average number of failure.

\section{REFERENCES}

[1] F. Medhioub, Z. Hajej, N. Rezg. A stochastic production planning optimization for multi parallel machine under leasing Contract. Probabilistic Safety Assessment \& Management conference. Hawaii, USA, June 22-27, 2014.

[2] $\mathrm{Hu}$, J., P. Vakili, and G. Yu, . Optimality of hedging point policies in the production control of failure prone manufacturing systems. Automatic Control, IEEE Transactions, 39 (9), 1875-1880, 1994.

[3] J. Pongpech, and D.N.P. Murthy "Optimal periodic preventive maintenance policy for leased equipment", Reliability Engineering \& System Safety, 91, pp. 772-777, 2006.

[4] J. P. kenne and L. J. Nkeungoue "Simultaneous control of production, preventive and corrective maintenance rates of failure prone manufacturing system". Applied Numeriacl Mathematics, 58, pp180-194,2008.

[5] Kenne, J. P. and Nkeungoue, L. J.. Simultaneous control of production, preventive and corrective maintenance rates of failure prone manufacturing system. Applied Numeriacl Mathematics, 58:180-194. 2008.

[6] Rezg, N.,Xie,X.,and Mati,Y. ,’Joint optimization of pre ventive maintenance and inventory control in a production line using simulation"; International Journal of Production Research, ,44,2029-2046, (2004).

[7] Wen-Liang-Chang, Ruey-Huei-Yeh, and Hui-Chiung-Lo. Optimal number of leased periods and maintenance policy with threshold value on age for leased equipment. APIEMS, pages 14-16. 2009.

[8] Wen-Liang-Chang, Hui-Chiung-Lo . Joint determination of lease period and preventive maintenance policy for leased equipment with residual value. Journal Computers and Industrial Engineering,Volume 61 Issue 3, Pages 489-496, 2011.

[9] Zied. H, Rezg. N, Askri. T. A production planning optimization for multi parallel machine under withdrawal right. International Conference on Industrial Engineering and Operations Management (IEEEIEOM), Dubai, 2015. 